\title{
Determination of a flexibility range for cellular manufacturing systems under product mix variations
}

\author{
H. SEIFODDINI $\dagger$ and M. DJASSEMI $\ddagger$
}

\begin{abstract}
One of the underlying assumptions in cellular manufacturing is that product mix is relatively stable over time. In this paper, a procedure for the sensitivity analysis of the performance of a cellular manufacturing system with respect to changes in the product mix is presented and a flexibility range representing the capability of the system in dealing with these changes is determined using simulation modelling. The simulation results in this study show that as the changes in the product mix increase the superiority of the performance of the cellular manufacturing system to the corresponding job shop system diminishes.
\end{abstract}

\section{Introduction}

One of the most significant transformations in batch type manufacturing in recent decades is the emergence of cellular manufacturing as a viable alternative to job shop manufacturing. In cellular manufacturing, production operations are organized in manufacturing units called 'machine cells.' Each machine cell is capable of processing a family of similar parts (part-family). Cellular manufacturing improves production systems through reduction in setup times, in-process inventories, and throughput times (Hyer and Wemmerlov 1984, Burbidge 1992).

Machine cells in cellular manufacturing are formed based on the data in the machine-part matrix which is a binary matrix with zero/one entries. The presence or absence of a 'one' entry in row $i$ and column $j$ of the matrix represent an operation of part or lack of it on machine $i$. Machine-part matrix represents machining requirements of parts in the product mix and has a significant impact on the performance of cellular manufacturing systems.

As the importance of cellular manufacturing in batch type production has increased so has the research effort in the area. As a result, numerous approaches to machine cell formation have been developed including machine-component group analysis (King and Nakornchai 1982, Chan and Milner 1982, Kusiak and Chow 1986), the similarity coefficient method (McAulley 1972, Carrie 1973, Seifoddini and Wolfe 1986, Balasubramanian and Panneerselvo 1993), the graph theoretic method (Rajagopalan and Batra 1982), and mathematical programming (Purcheck 1975, Gunasingh and Lashkari 1989, Shtub 1989). Numerous papers have been also published on comparative studies of job shop and cellular manufacturing systems (Flynn 1986, Sasani 1986, and Seifoddini and Djassemi 1995).

One of the implied assumptions in the modelling and development of cellular manufacturing systems is that the product mix is stable over the planning horizon. In

$\dagger$ Industrial and Manufacturing Engineering Department, The University of WisconsinMilwaukee, PO Box 784, Milwaukee, WI 53201.

¥Department of Industrial Studies, University of Wisconsin-Platteville. 
real world situations, however, product mix is a function of demand and it may well change as demand fluctuates. A few authors have tried to deal with the changing nature of product mix in the development of cellular manufacturing systems. Seifoddini (1990) has proposed a probabilistic machine cell formation model in which the expected value of intercellular material handling costs is used as a criterion for the selection among possible alternative machine cell configurations. Vakhria and Kaku (1993) have considered the impact of demand changes on the performance of cellular manufacturing systems. They have developed a procedure based on zero-one integer programming in which the allocation of parts in the product mix to machine cells is modified according to changes in the demand. A probabilistic zero-one integer programming model for machine cell formation has been also proposed by Harhalakis et al. (1994). This model seeks an optimal solution to the machine cell formation problem under a probabilistic demand.

In all the above cases, attempts have been made to develop a cellular manufacturing system that can accommodate changes in the product mix as effectively as possible. But even an optimally designed cellular manufacturing system for a specific range of variations in product mix, may not produce satisfactory results if the changes are beyond that range. It may well be economically preferable to keep the job shop system when the changes in the product mix are too great for the cellular manufacturing to be efficient. To determine what range of product mix changes can be accommodated by a particular cellular manufacturing system, it is necessary to evaluate the performance of such a system under a varying product mix.

In this paper a procedure for sensitivity analysis of the performance of cellular manufacturing systems under a varying product mix will be presented. In this procedure the capability of a cellular manufacturing system in dealing with changes in the product mix is determined by comparing the performances of a manufacturing system under job shop and cellular manufacturing for a range of product mix variations.

\section{Definition of the problem}

One of the very basic requirements in cellular manufacturing is the dedication of machine cells to the processing of part-families. This is contrary to the nature of job shop manufacturing in which general purpose machines can be set up according to the requirements of parts in the product mix thus providing the flexibility of dealing with continuous changes in demand. For this reason, the relative stability of product mix is a prerequisite for the satisfactory performance of cellular manufacturing systems. While a cellular manufacturing system outperforms its corresponding job shop system under the product mix for which it is designed, it may fail to do so if the product mix changes (Seifoddini 1990).

Due to the random nature of product demand in real world situations, the stability of the product mix is hardly achievable. Consequently, it is reasonable to determine a range of possible variations for the product mix under consideration for the development of a cellular manufacturing system. For a given manufacturing situation such a range can be used to determine the sensitivity of the performance of the corresponding cellular manufacturing system to the variations in the product mix. If the performance is satisfactory for the range of variations, then conversion from job shop to cellular manufacturing is justified. Therefore, better results can be achieved by the sensitivity analysis of a cellular manufacturing system with respect to product mix variations. 
The sensitivity analysis of the performance of cellular manufacturing systems subject to product mix variations serves two purposes. First, it determines whether a particular manufacturing situation is suitable for conversion to cellular manufacturing. Secondly, it can be used to evaluate the capability of a cellular manufacturing system in dealing with product mix variations.

Since the relative performance of a manufacturing system under job shop and cellular manufacturing is an important factor in the decision making about the development of cellular manufacturing systems, the comparative study of the performance of the two types of systems should be used to determine the capability of a cellular manufacturing system in dealing with variations in the product mix. There are numerous comparative studies of job shop and cellular manufacturing in the literature. One of the first such studies has been done by Shunk (1976) who compared the performance of a job shop with a hybrid layout (a combination of cellular and functional layout). Gupta and Tompkins (1982) performed a simulation study of a cellular manufacturing system under a surge in the demand for products. Flynn (1986) conducted a comparative study of a job shop and a cellular manufacturing system using simulation modelling. A comparative study of job shop and cellular manufacturing (Seifoddini and Djassemi 1995) has been used to determine a procedure for selection of machine-part matrices for the development of cellular manufacturing systems. These studies indicate that simulation modelling can be effectively employed in the study of manufacturing systems. They also provide a sound basis for the performance evaluation of a manufacturing system under job shop and cellular manufacturing and can be extended to include the effect of product mix variations on the performance of cellular manufacturing systems.

It is expected that in most cases, as the product mix deviates from its original structure, the performance of the cellular manufacturing system deteriorates due to inflexibility of dedicated machine cells. The impact of changs on the job shop system, on the other hand, will be less severe due to its flexibility in dealing with such changes.

In the next section a procedure for the sensitivity analysis of the relative performance of job shop and cellular manufacturing systems with respect to product mix variations will be developed.

\section{Methodology}

The composition of machines and machine cells in a cellular manufacturing system, to a great extent, is determined by the structure of the machine-part matrix, which in turn, is based on the processing requirements of parts in the product mix. The machine cell formation models, on the other hand, are designed to generate the best machine cell configuration based on the original machine-part matrix. Changes in the product mix lead to a new machine-part matrix which may result in a different machine cell configuration.

In practice, it is unlikely that one modifies the cellular manufacturing system to accommodate the changes in the new machine-part matrix. Consequently, it is necessary to determine how these changes affect the performance of the cellular manufacturing system. More importantly, it is necessary to determine the capability of the cellular manufacturing system in dealing with changes in the product mix. To do so, a sensitivity analysis of the performance of the cellular manufacturing system with respect to product mix variations is performed. 
For the performance evaluation in the sensitivity analysis, performance measures such as mean flow time, and work-in-process (WIP) inventories are used. The impact of changes on the performance of the cellular manufacturing system is evaluated by estimating the mean flow time and WIP inventories for the system under a varying product mix. To determine the capability of the cellular manufacturing system to deal with these changes, estimates of the mean flow time and WIP inventories for job shop and cellular manufacturing systems are compared. The range of changes in the product mix for which the performance of the cellular manufacturing system is superior to that of the job shop system is designated as the flexibility range of the cellular manufacturing system. More specifically, the flexibility range for a cellular manufacturing can be defined as:

Flexibility $=$ The percentage of changes in the product mix beyond which the cellular manufacturing system stops outperforming the corresponding job shop manufacturing system.

A simple way of defining the percentage of changes in the product mix is to calculate the ratio of new part types to the total number of part types. More accurate definition of the percentage is possible, but a more detailed analysis is needed to determine the most effective one and that is beyond the scope of this paper.

As mentioned earlier, simulation modelling is the only option in dealing with the complexity of manufacturing systems. In this study, simulation is used to estimate the mean flow time and WIP inventories for both job shop and cellular manufacturing systems under a varying product mix. To determine the statistical significance of the difference between the performance of the two systems, a paired- $t$ test will be employed.

The sensitivity analysis is performed in three phases. First, a machine-part matrix is used to develop a cellular manufacturing system. The machine-part matrix is chosen such that the associated cellular manufacturing system is superior to the corresponding job shop system. A simulation model for the performance evaluation of the manufacturing system under job shop and cellular manufacturing is developed. Then the mean flow time and WIP inventories for the two systems are estimated by simulation. Finally, variations in the product mix are introduced to the model and the simulation process is repeated for a range of variations. By comparing the performance of the job shop and cellular manufacturing system for a varying product mix, the range of changes for which the cellular manufacturing system keeps its superiority to the job shop system is determined. Such a range can be designated as the flexibility range of the cellular manufacturing system in dealing with product mix variations.

The procedure for the sensitivity analysis of the performance of a cellular system with respect to product mix variations can be presented as follows:

(1) Convert the machine-part matrix into a block diagonal form and develop the corresponding cellular manufacturing system. Use one of the machine cell formation algorithms such as ROC (King and Nacornchai 1982) or SCM (Seifoddini and Wolfe 1986).

(2) Develop a simulation model of the job shop and cellular manufacturing systems for performance evaluation.

(3) Estimate the mean flow time and WIP inventories for both systems by the simulation model and compare them by using paired- $t$ test. 
(4) Repeat step 3 for a varying product mix and determine the flexibility range of the cellular manufacturing system in dealing with product mix variations.

This procedure is a further step in the development of more effective cellular manufacturing systems. It provides more insight into the capability of a cellular manufacturing system through the sensitivity analysis of its performance.

\section{Simulation models}

A simulation model of a manufacturing system under job shop and cellular manufacturing configurations is developed to do the following,

(1) To generate demand, to assign parts to machine cells, to schedule the operations of part-families within each machine cell, to determine the setup times, and to measure the processing times.

(2) To handle the materials flow within and between machine cells,

(3) To estimate the mean flow time and WIP inventories of the manufacturing system.

The manufacturing sytem used in the simulation study is composed of 36 machines and 15 part types. It operates in a single shift of eight hours per day. There is one operator for every two machines. The demand for parts is exponentially distributed. Upon arrival the type of each part is determined and order is released to the shop floor for processing. Since the comparative study of job shop and cellular manufacturing configuration is involved, the set up times and processing times are assumed to be deterministic to eliminate the random variations between the performances in the two cases. The setup time for a part one machine is a function of its similarity to its predecessor part on the machine. The following coefficients are used to take into account this dependency,

(1) 1.0 : When the parts from two different part-families are loaded sequentially.

(2) 0.5 : When two parts from the same part-family are loaded sequentially.

(3) 0.1 : When two identical parts are loaded sequentially (just the loading and unloading times)

These coefficients are applied to a base setup time to calculate the setup time of a specific part.

Two models representing the job shop and cellular manufacturing configurations are developed. The job shop system accommodates 36 machines with 10 different functional types. The cellular manufacturing system is composed of five machine cells as presented in Fig. 1. The layouts of the manufacturing systems in the models are based on the assumption that each machine occupies one square unit. The distance between machines, department, and machine cells are rectilinear distances between their centres. Micro-CRAFT (Tompkins and Moor 1980) is used to deal with flow of materials in the two systems.

The simulation modelling in this study is based on SIMAN IV Simulation Language. The simulation is run for 350 days. The transient period for the simulation model is determined by a graphical model called 'replication deletion', (Law and Kelton 1991) The data collected over the transient period is discarded to minimize the variations due to the initial conditions. Two performance measures: mean flow time, and WIP inventories are estimated under a range of product mix variations. The first 60 days are used as the warm up period and the data collected over this 
PARTS TYPE

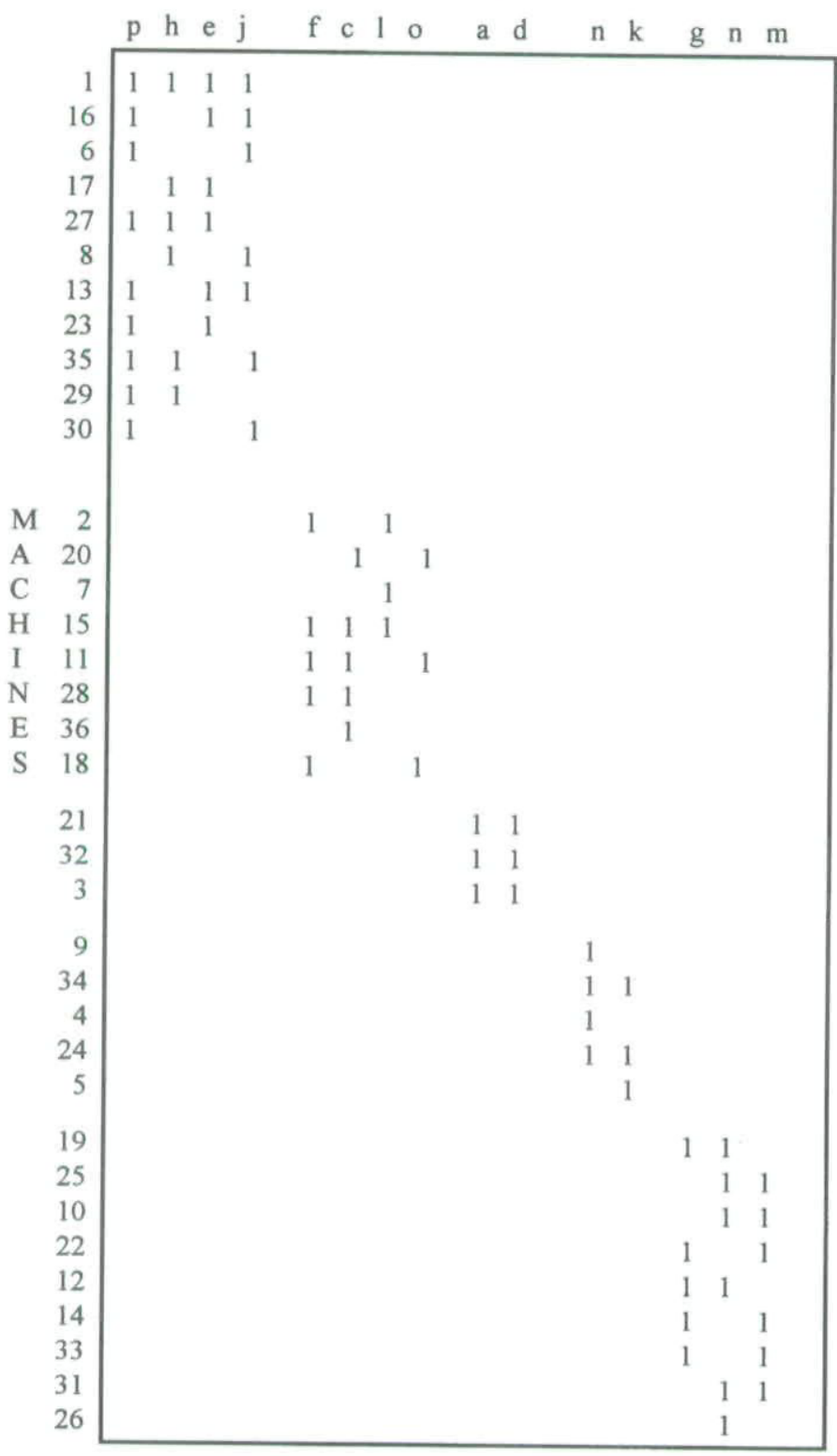

Figure 1. Machine-part matrix.

period is discarded. More detailed data on the modelling of the two systems are in Djassemi (1994).

To determine the statistical significance of the difference between the performance of the two types of system configurations, a paired- $t$ test will be employed. The following null hypothesis will be tested at $95 \%$ confidence level $(\alpha=0 \cdot 05)$. 
Hypothesis $\mathrm{H}_{0}$ : No difference exists between the performances of a job shop and cellular manufacturing system at a given percentage of change in the product mix. If this hypothesis is rejected for any percentage change in the product mix, then it can be concluded that product mix variations affect job shop and cellular manufacturing system differently and there will be a percentage change which makes the cellular manufacturing system less effective than the corresponding job shop system. The range of changes in the product mix bonded by this percentage can be designated as the flexibility range for the cellular manufacturing system.

In the next section, a numerical example will be used to demonstrate the application of the procedure to a manufacturing system under a range of product mix variations of up to $26 \%$.

\section{Analysis of results}

A manufacturing system composed of 36 machines and 15 part types has been used in the simulation study. The machine-part matrix for this manufacturing system is given in Fig. 1. The demand for parts in the product mix has poisson distribution with an arrival rate of $1 / 100$ part per minute. Variations in the product mix have been introduced through changes in part types. Due to the discrete nature of parts, the percentages of changes are not well rounded. Instead, changes in the product mix are expressed in $0,7,13,20$, and $27 \%$. The percentage of change in the product mix is calculated as:

$$
\frac{\mathrm{P}=\mathrm{n}}{\mathrm{N}}
$$

where,

$$
\begin{aligned}
& \mathrm{P}=\text { percentage of change } \\
& \mathrm{n}=\text { number of part changes } \\
& \mathrm{N}=\text { total number of parts }
\end{aligned}
$$

For simplicity, in this example it is assumed that the total number of part types remains the same, but some part types change with new demand. Machine-part matrices representing various percentage of changes in the product mix are the main inputs to the simulation model and are given in the Appendix.

Estimates of mean flow time and WIP inventories for the manufacturing system generated by the simulation model are given in Table 1. As can be seen in this table, as the percentage of changes in the product mix increases so do the mean flow time and WIP inventories. The mean flow time for the original matrix (percentage of change $=0$ ) is 68.0 . It increases to 108.8 when the product mix changes $27 \%$. The

\begin{tabular}{ccc}
\hline Product mix \% changes & Mean flow time & WIP inventories \\
\hline 0 & 68.0 & 0.99 \\
7 & 74.0 & $1 \cdot 19$ \\
13 & 78.8 & $1 \cdot 50$ \\
20 & 90.9 & 1.82 \\
27 & 108.8 & $2 \cdot 30$ \\
\hline
\end{tabular}

Table 1. Simulation results for cellular manufacturing system under product mix variations. 


\begin{tabular}{|c|c|c|c|c|c|c|}
\hline \multirow{2}{*}{$\begin{array}{l}\text { Product mix } \\
\text { change }(\%)\end{array}$} & \multicolumn{2}{|c|}{$\mathrm{CM}$} & \multicolumn{2}{|c|}{ Job shop } & \multicolumn{2}{|c|}{$\Delta$ and $95 \%$ C.I. } \\
\hline & Flow time & WIP & Flow time & WIP & Flow time & WIP \\
\hline 0 & 68 & 0.99 & $92 \cdot 6$ & $2 \cdot 1$ & $23 \cdot 5 \pm 3 \cdot 2$ & $1.2 \pm 0.2$ \\
\hline 7 & $85 \cdot 2$ & $1 \cdot 6$ & 94.8 & 1.95 & $8 \cdot 4 \pm 1 \cdot 1$ & $0 \cdot 4 \pm 0 \cdot 1$ \\
\hline 13 & 107 & $2 \cdot 13$ & 104 & $2 \cdot 21$ & $2 \cdot 7 \pm 1 \cdot 4$ & $0.07 \pm 0.09$ \\
\hline 20 & 135 & $2 \cdot 9$ & 113 & $2 \cdot 7$ & $21 \pm 2 \cdot 1$ & $0 \cdot 2 \pm 0.05$ \\
\hline 27 & 146 & $3 \cdot 1$ & 116 & $2 \cdot 7$ & $29 \pm 1.7$ & $0.4 \pm 0.08$ \\
\hline
\end{tabular}

Table 2. Simulation results for job shop and cellular manufacturing systems under product mix variations.

changes in WIP inventories is even more dramatic (from 0.99 to 2.30 ) as the percentage of change in the product mix increases from 0 to $27 \%$. Therefore, the deviation from the original product mix in the machine-part matrix adversely affects the performance of the cellular manufacturing system.

The next step in this study is the determination of the flexibility range for the cellular manufacturing system. Since the flexibility range represents the capability of the cellular manufacturing system in dealing with the product mix variations, a comparative study of the manufacturing system under job shop and cellular manufacturing is necessary. This is so because a cellular manufacturing system is desirable as long as it outperforms the corresponding job shop system. Thjerefore, the percentage of changes in the product mix at which the cellular manufacturing system ceases to outperform the job shop system can be used to determine the flexibility range of the cellular manufacturing system.

The simulation results for the manufacturing system under job shop and cellular manufacturing are summarized in Table 2. As in the previous case, increase in the percentage of product mix variations (from 0 to $27 \%$ ) leads to the deterioration in performance of both systems. The cellular manufacturing system, however, is more dramatically affected by changes. The mean flow time for the job shop system increases from 92.6 to 116.0 , an increase of about $25 \%$ (for product mix variations of 0 to $27 \%$ ). The corresponding change in the mean flow time of the cellular manufacturing system is more than $100 \%$.

Based on the simulation results (Table 2) for small changes in the product mix $(0-7 \%)$, the cellular manufacturing system maintains its superiority in terms of mean flow time and WIP inventories to the job shop system. As the percentage of change in the product mix increases (7-13\%) the performances of the two systems becomes less distinct. Finally, the large changes in the product mix ( $20 \%$ or more), the cellular manufacturing system is no longer desirable and the job shop has a superior performance (Table 2).

A graphical comparison of the performances of the job shop and cellular manufacturing systems in terms of mean flow time as a function of product mix variations is given in Fig. 2. The graph shows that under the original product mix, the cellular manufacturing system clearly outperforms the job shop system. When the percentage of changes is in the neighbourhood of $13 \%$ the two systems hardly differ in terms of mean flow time. As the percentage of change in the product mix approaches $20 \%$ or more, the difference between the performances of the two systems dramatically increases and the job shop system becomes a preferred manufacturing system. 

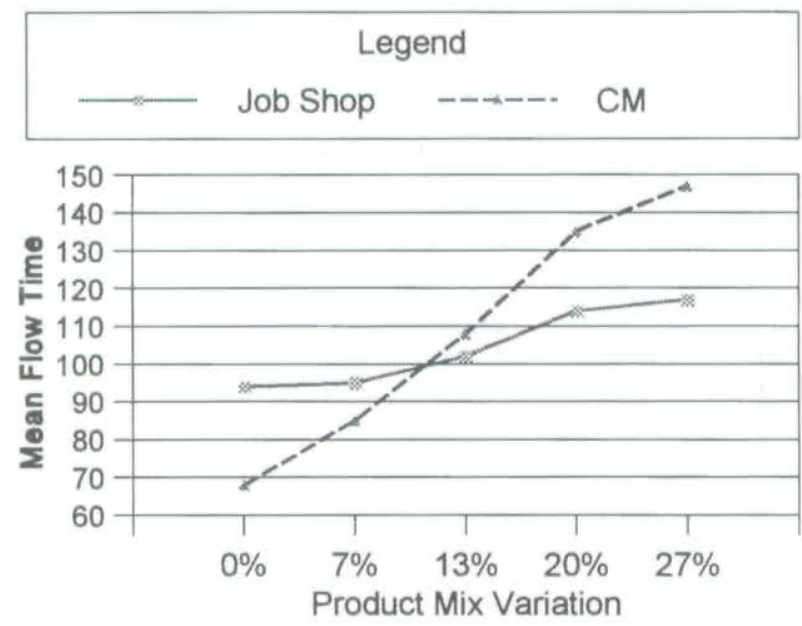

Figure 2. Mean flow time vs product mix variations for job shop and cellular manufacturing systems.

Based on the simulation results in this study, the job shop system is more capable of dealing with product mix variations. While the cellular manufacturing system in this study could tolerate small changes in the product mix, it could not maintain its superiority to the job shop system at high percentage of changes in the product mix. For this specific example, one can choose the range of 0 to $13 \%$ as the flexibility range for the cellular manufacturing system.

This study contributes to better understanding of cellular manufacturing systems in two ways. First, it shows, as expected, that product mix variations may adversely affect the performance of a cellular manufacturing system. Secondly, the procedure presented here can be used to evaluate the capability of a cellular manufacturing system in dealing with product mix variations. The concept of a flexibility range for cellular manufacturing system is very useful because it provides a quantitative basis for evaluating a cellular manufacturing system to determine its effectiveness in a changing environment.

\section{Conclusion}

A procedure for the sensitivity analysis of the performance of cellular manufacturing systems to product mix variations has been presented. The simulation results show that changes in the product mix lead to the deterioration of the performance of the cellular manufacturing system, in terms of mean flow time and WIP inventories in the sample employed here.

The procedure presented here can be used to evaluate the capability of a cellular manufacturing system in dealing with product mix variations. The comparative study of a manufacturing system under job shop and cellular manufacturing provides a basis for determining the flexibility range of the cellular manufacturing system. 


\section{Appendix}

PARTS TYPE

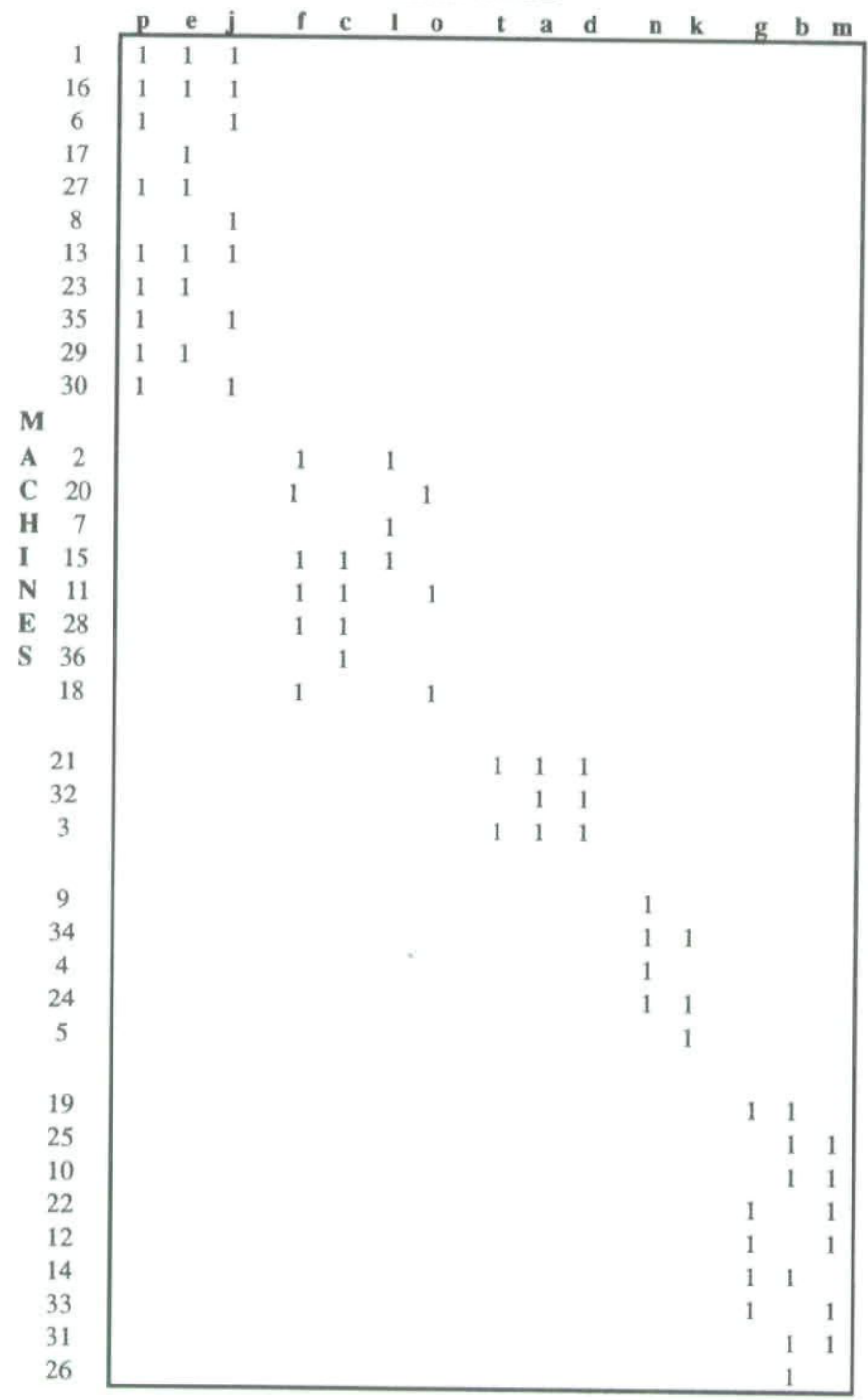

Figure 3. M-P matrix after replacing one part ( $6 \%$ changes in part mix). 


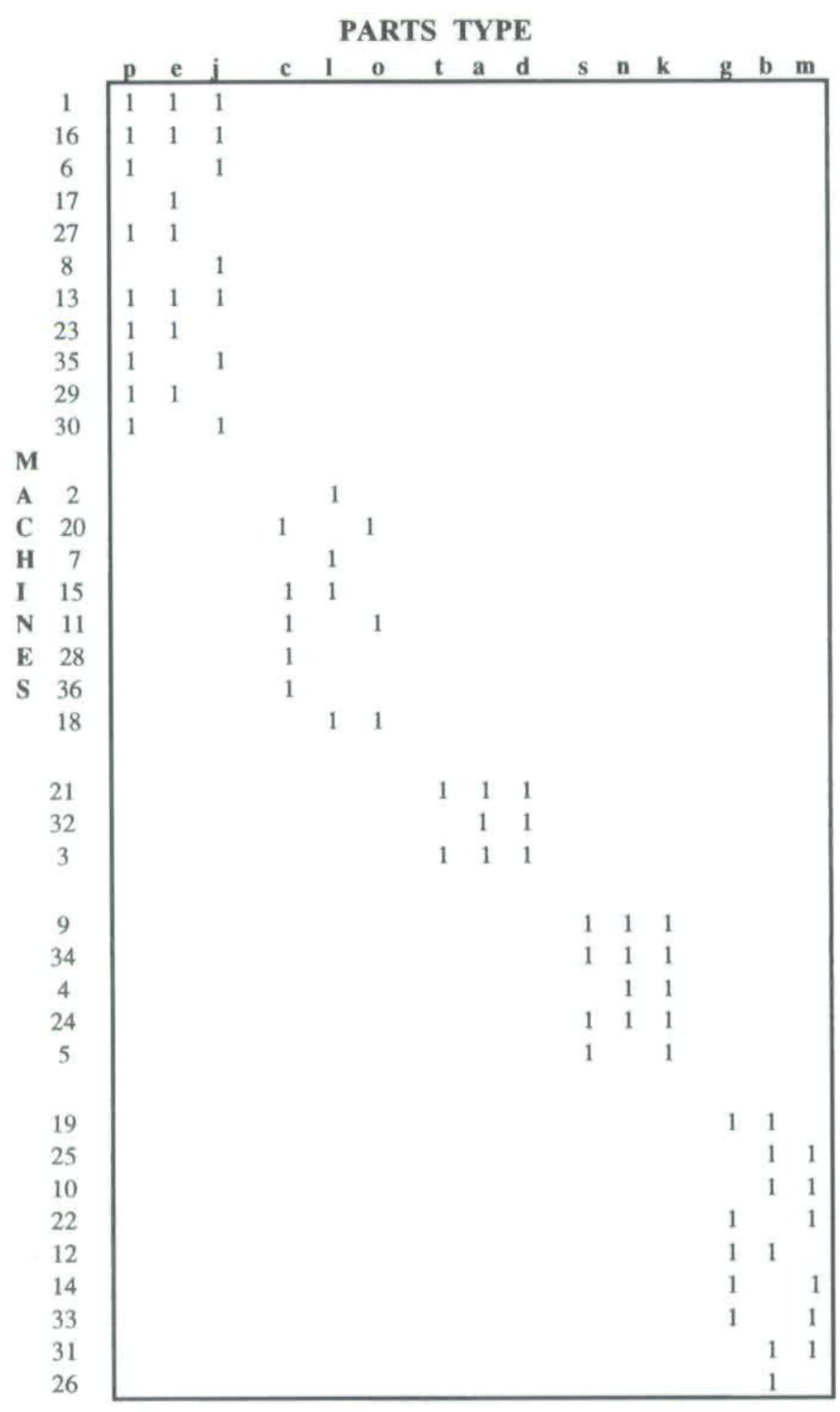

Figure 4. MP matrix after replacing two part types ( $13 \%$ change in part mix). 


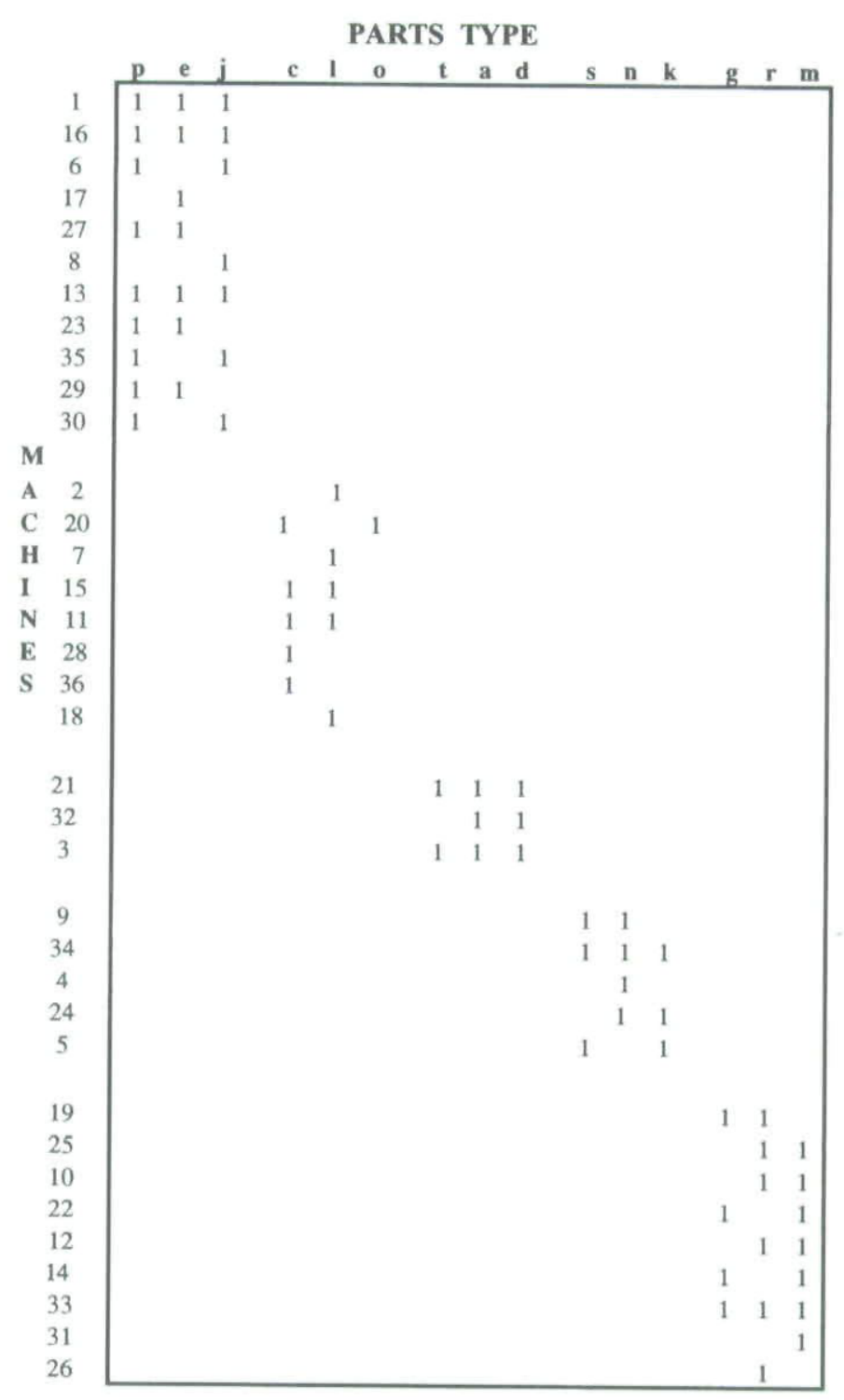

Figure 5. M-P matrix after changing the part-mix by $20 \%$ (replacing 3 part types). 


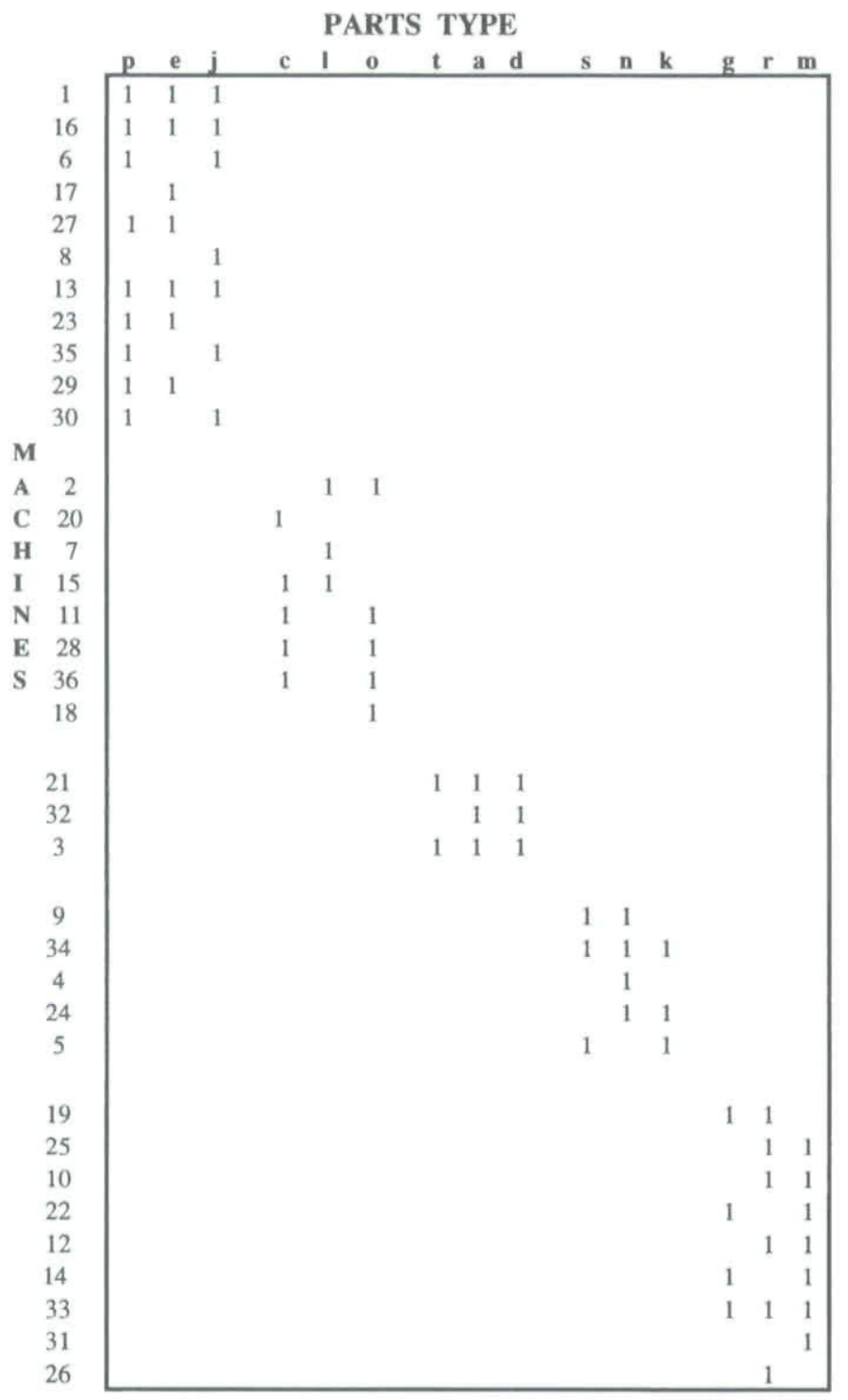

Figure 6. M-P matrix after changing the part mix by $26 \%$ (replacing 4 part types). 


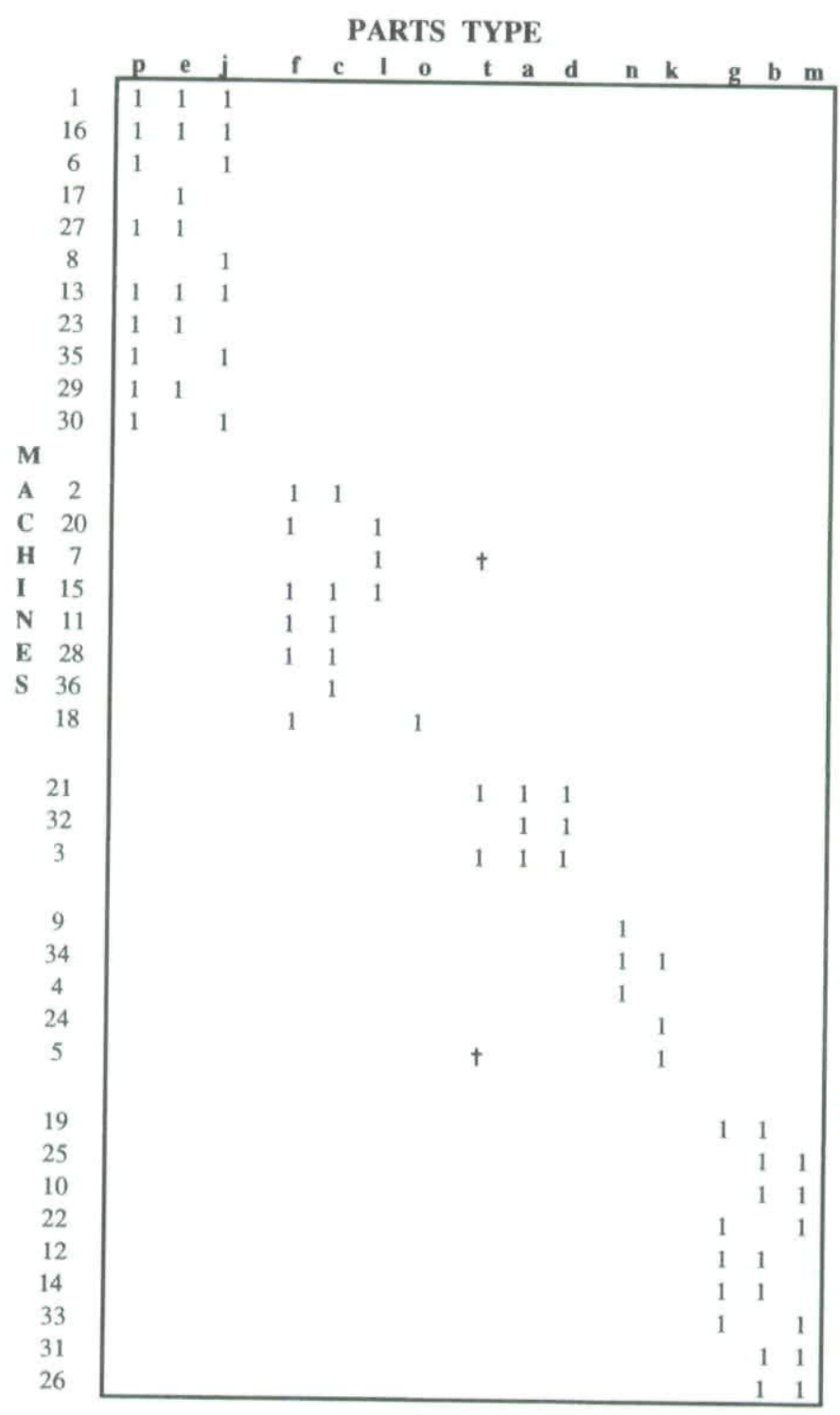

Figure 7. Part mix is changed by $6 \%$ with intercellular moves. 


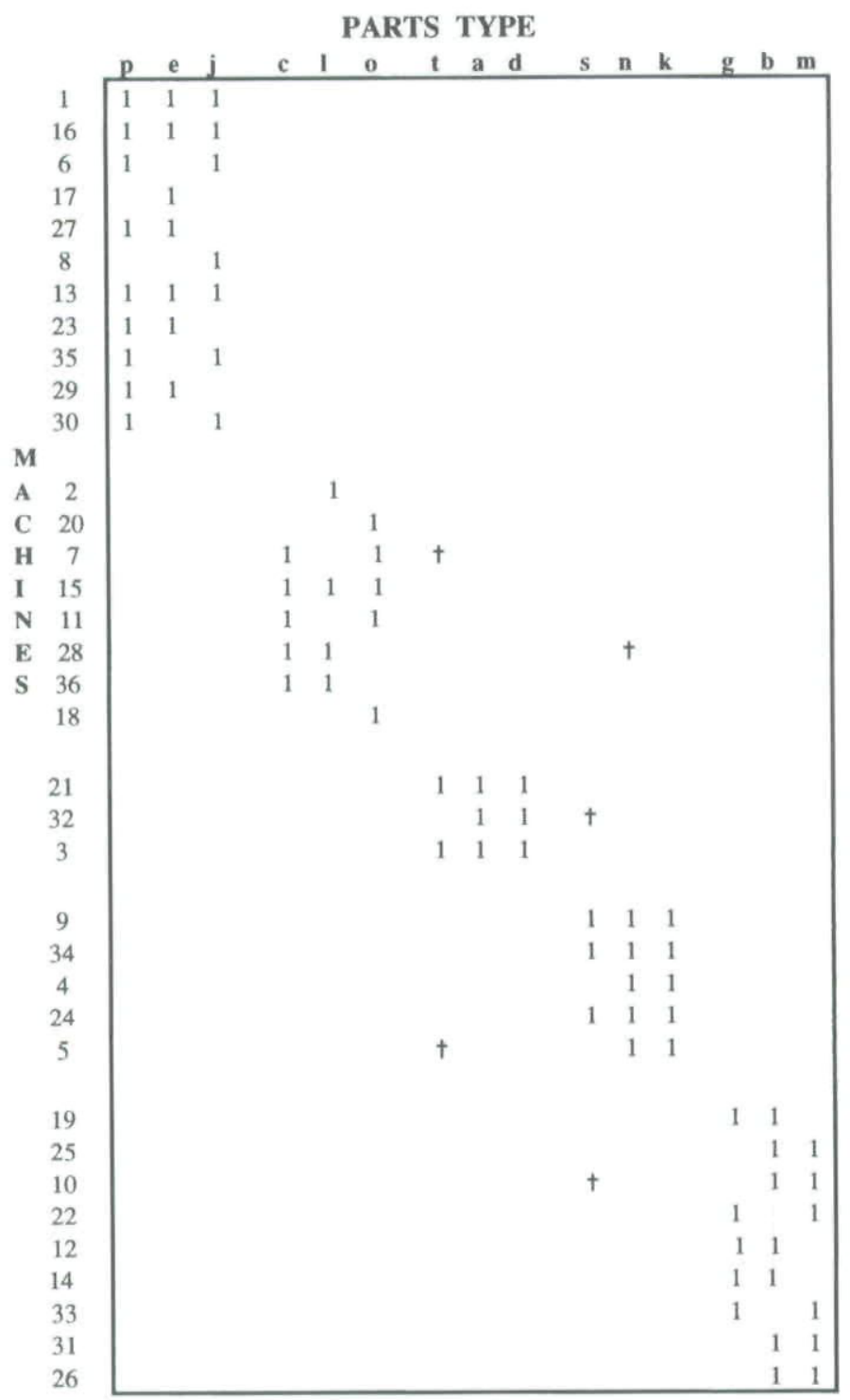

Figure 8. Part mix is changed by $13 \%$ with intercellular moves. 
PARTS TYPE

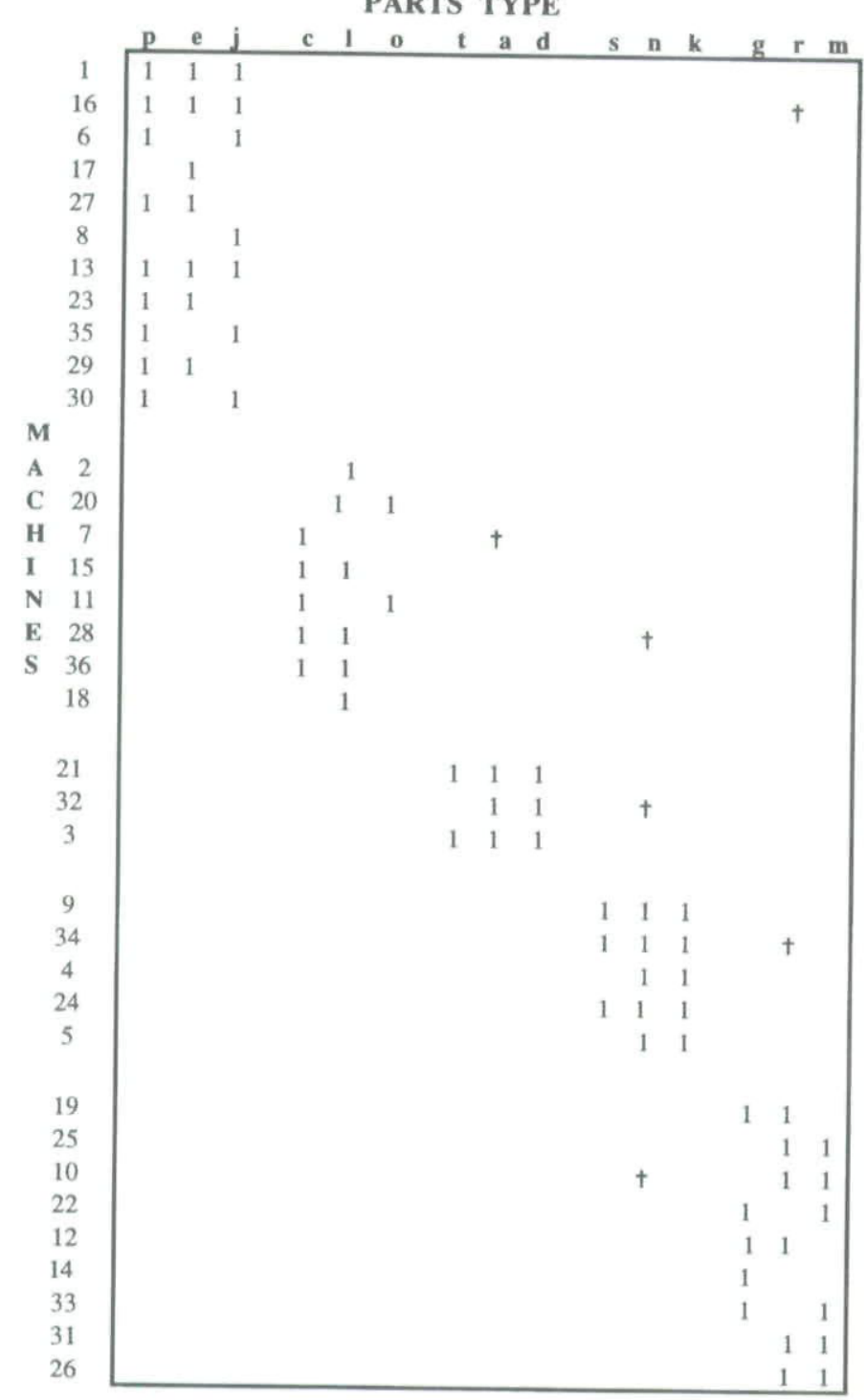

Figure 9. Part mix is changed by $20 \%$ with intercellular moves. 
PARTS TYPE

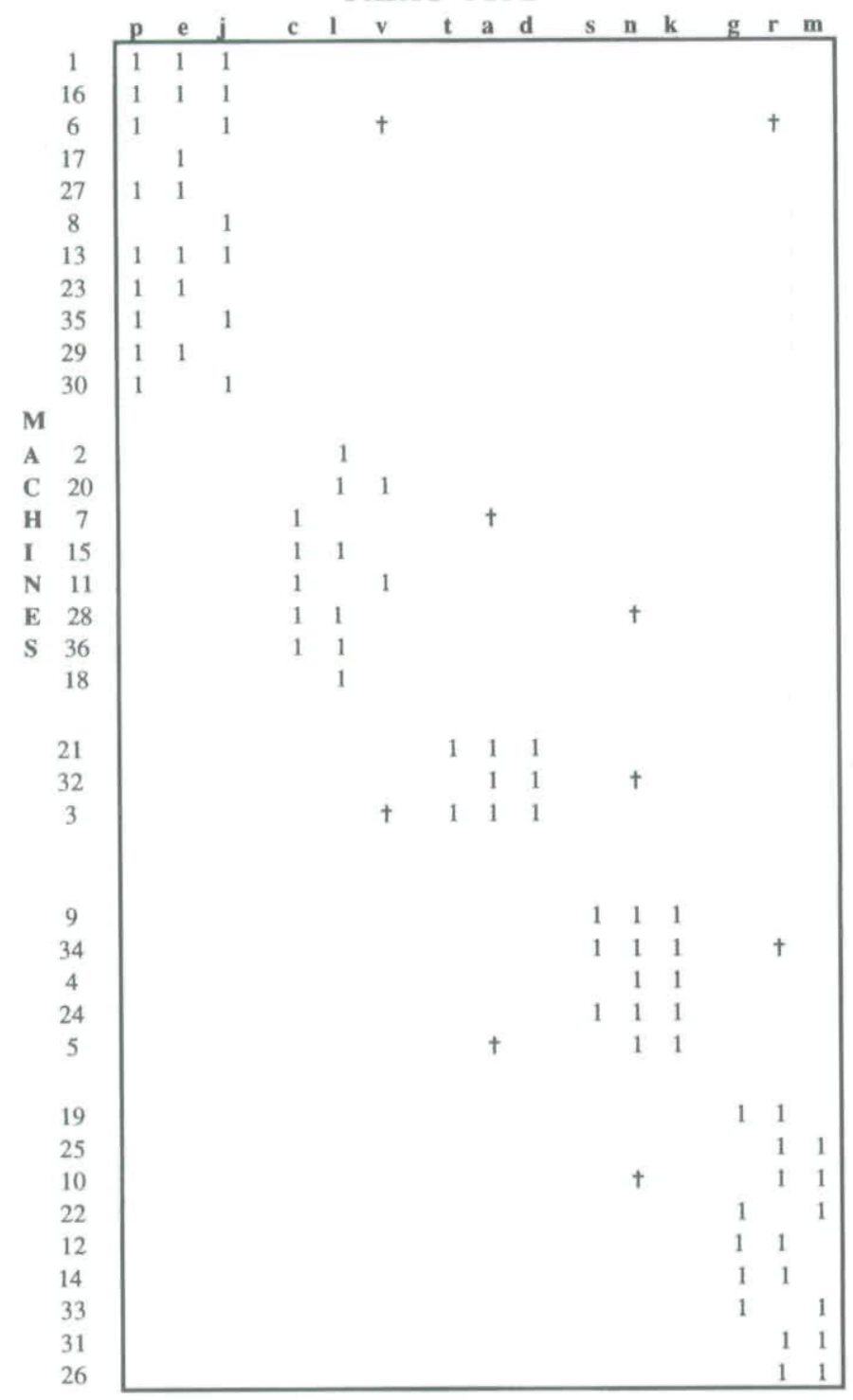

Figure 10. Part mix is changed by $20 \%$ with intercellular moves.

\section{References}

Balasubramanian, K. N., and Panneerselvo, R., 1993, Covering technique-based algorithm for machine grouping to form machine cells. International Journal of Production Research, 31, 1479-197.

BURBIDGE, J., 1992, Change of group technology: process organization is obsolete. International Journal of Production Research, 30(5), 1209-1220.

Burbidge, J., 1975, The Introduction of Group Technology (New York: Wiley).

CARRIE, A., 1973, Numerical taxonomy applied to group technology and plant layout. International Journal of Production Research, 11 (4), 399-416.

Chan, H. M., and Milner, D. A., 1982, Direct clustering algorithm for group formation in cellular manufacturing. International Journal of Production Research, 1(1), 65-81. 
Chandrasekharan, M. P., and Rajagopalan, R., 1989, Groupability: an analysis of the properties of binary data matrices for group technology. International Journal of Production Research, 27(6), 1035-1052.

DJASSEMI, M., 1994, The use of machine grouping efficiency in comparison of job shop and cellular manufacturing systems: a simulation study. $\mathrm{PhD}$ thesis. Department of Industrial and Manufacturing Engineering, University of Wisconsin-Milwaukee.

GUNASINGH, K. R., and LASHKARI, R. S., 1989, Machine grouping problem in cellular manufacturing sytsems: an integer programming approach. International Journal of Production Research, 27, 1465-1473.

GUPTA, R. M., and TOMPKINS, J. A., 1982, An examination of the dynamic behaviour of partfamilies in group technology. International Journal of Production Research, 20(1), 7386.

Harhlakis, G., IoAnNou, G., Minis, J., and NaGi, R., 1994, Manufacturing cell formation under random product demand. International Journal of Production Research, 32 (1), $47-64$.

Hyer, N. L., and Wemmerlov, U., 1984, Group technology and productivity. Harvard Business Review, July/August.

KING, J. R., and NACORNCHAI, V,, 1982, Machine-component group formation in group technology: review and extension. International Journal of Production Research, 20(2), $117-133$

KusiaK, A., and CHOW, W. A., 1986, Efficient solving of group technology problems. Journal of Manufacturing Systems, 6(2), 118-124.

LAw, A. M., and Kelton, W. D., 1991, Simulation Modeling and Analysis. (New York: McGraw Hill).

MCAulley, J., 1972, Machine grouping for efficient production. The Production Engineer, $52(2), 53-57$.

PURCHECK, G. F. K., 1975, A mathematical classification as a basis for the design of group technology production cells. Production Engineer, 54(1), 35-48.

Rajagopalan, R., and Batra, J. L., 1982, Design of cellular production systems: a graphtheoretic approach. International Journal of Production Research, 13(6), 567-579.

SASANI, F., 1990, A simulation study on performance improvement of group technology cells. International Journal of Production Research, 28(2), 293-300.

SEIFoddini, H., and Wolfe, P., 1986, Application of the similarity coefficient method in group technology. IIE Transactions, 18(3), 271-277.

SeIfoddini, H., and DJASSEMI, M., 1995, Selection of machine-component charts for cellular manufacturing based on quality index. Proceedings of 4th Industrial Engineering Research Conference, Nashville, Tennessee,

SEIFoddini, H., 1990, A probabilistic model for machine cell formation. Journal of Manufacturing Systems, 9(1), 69-75.

ShtuB, A., 1989, Modeling group technology cell formation as a generalized assignment problem. International Journal of Production Research, 27, 775-782.

ShunK,D., 1976, The measurement of the effects of group technology by simulation. PhD thesis, Purdue University.

Tompkins, J. A., and Moor, M. J., 1980, Computer-aided layout: a user guide. Monograph series, 1, IIE Facilities Planning and Design Division.

VAKHARIA, A. J., and KAKU, B. K., 1993, An investigation of the impact of demand changes on a cellular manufacturing system. Technical Report MS1593-001, College of Business and Management, University of Maryland. 